\title{
UPPER AIRWAY VOLUMETRIC CHANGE FOLLOWING THE USE OF TWO CAD/CAM ORAL APPLIANCES FOR TREATMENT OF OBSTRUCTIVE SLEEP APNEA
}

\author{
Mervat E. Abd Ellah ${ }^{1 *} M S c$, Faten S. Abbas ${ }^{2} P h D$, Mohamed M. Khamis ${ }^{2} P h D$, Nashwa H,
} Abdel Wahab ${ }^{3} P h D$, Amr M. Ekram ${ }^{4} P h D$

ABSTRACT

INTRODUCTION: Obstructive sleep apnea (OSA) is a condition in which there is repetitive and intermittent occlusion of the upper airway (UA) during sleep. OSA can be treated through; continuous positive airway pressure (CPAP), surgery, or oral appliances. Mandibular Advancement Appliance (MAA) is considered a valid alternative, which can be the first choice in simple snorers and mild-moderate OSA. MAA can be either custom-made or non-custom-made, one-piece or two-piece, titratable or non-titratable. While Monoblock designs permit no mouth opening, two-piece appliances vary in permissible lateral jaw movement and in the coupling mechanisms which attach the two plates together.

OBJECTIVES: measuring the change in UA volume after the use of two different designs of MAA (Monoblock and Biblock)

MATERIALS AND METHODS: Twenty patients with diagnosed OSA were divided randomly into two equal groups: Monoblock group ; received Monoblock MAA fabricated using CAD/CAM technique at different advancement levels; $50 \%$ then $75 \%$ of maximum advancement, Biblock group; received Biblock MAA fabricated using CAD/CAM technique at different advancement levels; 50\% then 75\% of maximum advancement. UA volume of all patients were evaluated after three months of acclimatization of each stage of advancement through Cone-Beam Computed Tomography (CBCT).

RESULTS: Biblock group showed statistically significant increase in UA volume at $75 \%$ mandibular advancement level, compared to Monoblock group ( $\mathrm{p}=.001)$. There was statistically significant increase in UA volume percentage change from baseline to $50 \%$ advancement $(\mathrm{p}=.016)$, and also from baseline to $75 \%$ advancement $(\mathrm{p}=.001)$ in favor to Biblock MAA.

CONCLUSIONS: Both Monoblock and Biblock MAA produced statistically significant increase in UA volume of OSA patients. Biblock MAA with elastics presented statistically significant favorable increase in UA volume in relation to Monoblock MAA.

KEYWORDS: Sleep Apnea, biblock appliance, mandibular advancement, airway measurement, monoblock appliance.

1 Assistant lecturer of Removable Prosthodontics, Faculty of Dentistry, Alexandria University

2 Professor of Removable Prosthodontics, Faculty of Dentistry, Alexandria University

3 Professor of Chest Diseases, Faculty of Medicine, Alexandria University

4s Oral and Maxillofacial Surgery consultant, Faculty of Dentistry, Cairo University.

*Corresponding author:

E-mail: mervodoctor2007@hotmail.com

\section{INTRODUCTION}

The international classification of sleep related breathing disorders falls into three basic categories: central sleep apnea syndrome, obstructive sleep apnea syndrome (OSAS), and sleep-related hypoventilation/hypoxia syndrome (1).

Obstructive sleep apnea (OSA) is a condition in which there is repetitive and intermittent occlusion of the upper airway (UA) during sleep. This closure occurs due to inspiratory collapse of the pharyngeal walls. If complete closure occurs, it results in apnea; if partial closure occurs, hypopnea results (2).

Many treatment modalities for OSA have been suggested such as; continuous positive airway pressure (CPAP), surgery, or oral appliances (OAs). CPAP has been the treatment of choice as it is generally considered the "gold standard" treatment for OSA. It needs sealed tubing and a power source connected device with the use of mask interface (3).

However, CPAP is not always tolerated by patients, and it is used less frequently than medically required (4). Nasal congestion and mask intolerance are the most common complaints that reduce CPAP compliance (5).

Furthermore, surgical treatment may have serious side-effects like scarring in soft palate (3). As an alternative, oral appliances can be prescribed to prevent UA collapse during sleep, especially for mild and moderate cases (6). 
Common terms of oral appliances used for OSA include, but are not limited to: mandibular advancement device (MAD), mandibular repositioning device (MRD), mandibular advancement splint (MAS), and mandibular advancement appliance (MAA). There are also OAs that hold the tongue forward and are called tongue retaining devices (TRDs). There was insufficient evidence to assess the efficacy of TRDs for the treatment of adult patients with OSA (7).

The American Sleep Disorders Association defines MAA as a device which is introduced into the mouth and modifies the position of the jaw, the tongue and other supporting structures of the UA for the treatment of chronic snoring and OSA (7).

MAA is considered as a valid alternative, which can be the first choice in simple snorers, mild OSA patients, mild-moderate OSA with low body mass index, and patients suffering from the syndrome of increased resistance of the UA; and a second choice in patients who do not improve or cannot tolerate positive pressure devices, patients at high surgical risk and who react badly to surgical treatment (8).

Custom OA is commonly fabricated using digital or physical impressions and models of an individual patient's oral structures. It is made of biocompatible materials and engages both the maxillary and mandibular arches (9). Non-custom OAs are primarily prefabricated and usually partially modified to an individual patient's oral structures (7).

In addition to being custom or non-custom-made, MAA can be either a one-piece (Monoblock) or a twopiece (Biblock) appliance, and can be also either titratable or non-titratable appliance (10). Biblock MAA is usually adjusted using a screw located in the midline, anteriorly or in the palate, or laterally with arms of different lengths or screws on both sides of the appliance (11). Monoblock MAA permit no mouth opening, but some designs permit the opening of the mandible (two-piece design; separate upper and lower plates) and some lateral movement, while others fixate the jaws more rigidly (12). The use of rigid MAA restricts mandibular movement and this immobility sometimes produces discomfort and may be temporomandibular disorders (13). Biblock MAA also varies in permissible lateral jaw movement and in the coupling mechanisms which attach the two plates together (12).

Titratable OAs have a mechanism that allows for varying amounts of mandibular protrusion while nontitratable OAs hold the mandible in a single protrusive position, and no changes are possible over the course of treatment (7).

However, a meta-analysis of 27 Randomized Clinical Trials including 1,054 patients suggested that custom, titratable and custom, non-titratable OAs achieve an equivalent reduction in Apnea Hypopnea Index (AHI) in adult patients with OSA (7).

On the same line, AbdElmoniem (14) concluded in a study that no significant difference in the treatment outcome when fixed mandibular advancement position
(FMAP) and adjustable mandibular advancement position (AMAP) were compared. The author added that whenever possible FMAP should be first selected if OAs are indicated because of its simple design and cost effectiveness (14).

MAA carries out an anterior and inferior movement of the jaw, generating anatomical variations in the UA that enable an increase in the pharyngeal area (2). Although its main effect appears in the velopharyngeal area, it has repercussions for all the pharyngeal

segments (11)

The degree of mandibular advancement is an important modulator of the treatment outcome, since there is a dose-dependent effect on nocturnal oxygenation and pharyngeal collapsibility. A small advancement produces a less satisfactory effect, while too large advancement produces more treatment effect (11).

Excessive advancement produces more sideeffects. Inappropriately large mandibular advancements should be avoided, since the long-term negative sideeffects on occlusion and the temporomandibular joints are unknown (11).

Few published trials reported using the elastic mandibular advancement for treatment of OSA, especially the custom one, which is proposed to produce less discomfort for the patients and less temporomandibular side effects.

Thus, this research, based on a pilot study, aimed to introduce a technique for direct construction of Biblock MAA with orthodontic elastics and Monoblock MAA fabricated using Computer Aided Designing and Computer Aided Manufacturing (CAD/CAM) procedure and evaluates them for patients with OSA. In addition, evaluation of volumetric change in the UA space using the application of cone-beam computed tomography (CBCT) following their use by OSA patients.

\section{MATERIALS AND METHODS}

This study was performed after obtaining the approval of the ethical committee of the faculty of dentistry, Alexandria University, Egypt. The protocol for this study was registered in the Pan African Clinical Trial Registry (www.pactr.org) database (Cochrane South Africa) with unique identification number (PACTR201806003371275). To carry out this study, a sample of twenty adult patients with mild-moderate obstructive sleep apnea (OSA) diagnosed using full polysomnography and refused to use CPAP was selected from those admitted to the center of sleep disorders at department of diseases of the chest, Faculty of Medicine, Alexandria University. This sample size was calculated using, PASS program version 20 , in reference to Sharma et al (15) and Aarab et al, (16) and was found to be adequate to estimate the expected scores needed for this study. (Sample size calculation. Biostatistics department. High institute of public health. Alexandria University).

All selected patients in this study had successfully completed all night polysomnography that demonstrated an OSA disorder with mild (5-15) to moderate (15-30) 
apnea hypopnea index (AHI) score. They were selected to have at least $7 \mathrm{~mm}$ of protrusive jaw movement from the position of maximum intercuspation, measured by flexible ruler. Patients with central sleep apnea events, previous history of treatment with any type of OSA prostheses, or had more than one missing tooth per quadrant except for third molars were excluded.

A written informed consent was obtained from each patient accepting to share in this study after explaining the procedures to them.

Each patient received two MAAs for treatment of OSA with two different mandibular advancement levels (MAL). They were randomly allocated (single blinded) into two equal groups (each 10) according to the type of MAA using Research Randomizer online software (http://www.randomizer.org) (17). All MAA were fabricated using CAD/CAM technology.

Monoblock Group: received Monoblock MAA at two different MAL for two stages, three months each.

- Monoblock subgroup 1 (first stage): 50\% MAL.

- Monoblock subgroup 2 (second stage): 75\% MAL

Biblock Group: received Biblock MAA (both mandibular and maxillary parts were attached to each other by orthodontic elastic bands) at two different MAL for two stages, three months each.

- Biblock subgroup 1 (first stage): 50\% MAL.

- Biblock subgroup 2 (second stage): 75\% MAL.

I. Pre- prosthetic phase:

(a) Patient's initial general evaluation:

- At the initial diagnostic phase, the patients were asked to fill a comprehensive questionnaire and examination chart regarding their medical condition. Moreover, a thorough intra-oral clinical examination was performed.

- STOP BANG questionnaire as a screening tool for OSA was performed to each patient (18).

(b) Overnight polysomnography PSG (SOMNOmedics

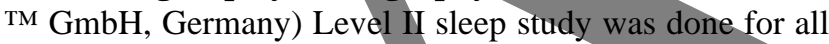
patients to confirm OSA diagnosis. Sleep stages and arousals, AHI, periodic limb movement, and nocturnal blood pressure were assessed in addition to respiratory events (4).

(c) CBCT (SOREDEX, SCANQRA 3Dx. Finland) was done for each patient prior to construction of MAA serving as baseline.

All patients sat upright with the chin supported on an adjustable platform and the Frankfort horizontal plane parallel to the floor while the rotating source detector captured a volumetric image of the patient's head. Immediately before scanning, all patients were instructed to keep their teeth in contact throughout the scanning process (19).

Each patient was asked to hold his or her breath after the end of expiration, without swallowing, because the pharyngeal airway caliber when awake is smallest at this time. Breath holding at this moment provides a static pharyngeal airway size that can be recorded consistently in all CBCT scans, thereby reducing variations caused by changes in pharyngeal airway caliber during the respiratory cycle (20). This position is stable and has high reproducibility for measurement. The image detector and beam were positioned to maximize coverage of the UA.

A CBCT device (SOREDEX, SCANORA 3Dx. Finland) with a large field of view $(14.0 \mathrm{~cm} \times 16.5 \mathrm{~cm})$ was set to maximum $90 \mathrm{kV}$, maximum $10 \mathrm{~mA}$, and exposure time of 10 seconds. Data was sent directly to a personal computer and stored in Digital Imaging and Communications in Medicine (DICOM) format.

\section{II- Prosthetic phase:}

A. Recording of interocclusal protrusive records For both groups with MAA either Monoblock or Biblock

- Maxillary and mandibular impressions with irreversible hydrocolloid impression material (Cavex CA37, Holland BV, Haalem, Netherlands) were made on stock tray to produce stone casts.

- Optical scanning (3Shape scanner, D850, Denmark) of the maxillary and mandibular casts was performed to obtain virtual digital models.

- Interocclusal protrusive records at 50\% MAL were made according to the following steps (16);

1) A line was drawn intraorally on the buccal surface of the first maxillary and mandibular premolars at both sides at the maximum intercuspation position with indelible pencil.

2) Each patient was asked to fully protrude the mandible. The maximum amount of protrusion was measured intraorally with a ruler between the previous drawn lines on the first maxillary and mandibular premolars.

3) $50 \%$ MAL was calculated, then the patient was guided to protrude the mandible to this distance with approximately 6-8 $\mathrm{mm}$ vertical space from the incisal edges of the anterior teeth (21). This was done using tongue wooden depressors, each represent $1 \mathrm{~mm}$ thickness. 4) Occlusal recording material (Bona-Bite, DMP, The Villages, U.S.A) was injected bilaterally between maxillary and mandibular teeth at 50\% MAL.

5) Maxillary and mandibular casts were aligned with $50 \%$ MAL record then scanned (3Shape scanner, D850, Denmark) and transferred to the related CAD/CAM software to get virtual digital model. Each virtual digital model was registered to its actual alignment in reference to the MAL record scan to obtain the exact maxillomandibular relation needed for appliance fabrication.

- The same steps were repeated for 75\% MAL record.

\section{B) Designing of MMA}

- The virtual models were imported for registration using the multipoint registration and best fit alignment command.

- The CAD software (PLASTYCAD, 3DIEMME. Italy) was used to design the two different MAA as follows;

\section{For Monoblock MAA (Fig. 1)}

- The design of the appliance was outlined on the maxillary and mandibular casts in the form of horse shoe plates then fused together to get one-piece MAA at each specific MAL. 


\section{For Biblock MAA (Fig. 2)}

- The design of the appliance was outlined on the maxillary and mandibular casts in the form of horse shoe plates to get two-piece MAA.

- This appliance had an interlocking acrylic step (bite pads) which was fabricated on both arches at the premolarmolar areas to maintain the recorded protrusive position.

- Four retentive acrylic buttons on each arch, two on each side, were designed to retain inter arch orthodontic elastics (ORMCO Z-pack elastics, Mexico) that were inserted finally in the patient's mouth using elastic placer.

- The orthodontic elastics at the side parts were used to support the front connection and permit some lateral movement at the same time.

\section{C) Manufacturing of MAA}

- An order was given to the CAD machine (Planmeca $\mathrm{Creo}^{\mathrm{TM}}$, Helsinki, Finland) to print the designed appliance using printable resin material (NextDent, Netherlands).

- The supports of the prints were mechanically removed, and then the prints were washed using alcohol to remove any excess uncured resin

- The prints were seated on their corresponding casts then placed in the UV post-curing machine (Otoflash post curing light pulsing unit, Envision TEC Inc., Dearborn, Michigan, U.S.) for 400 seconds to get the optimal retention and adaptation of the printed appliances.

D) Insertion of MAA (Fig. 3, 4)

- MAA of each group was inserted intraorally and was checked for adaptation and retention.

- Patients were instructed to wear the denture only during sleeping.

- For group B (Bíblock MAA) patients were educated how to put the elastics in the exact position

- Oral hygiene instructions were given to each patient including cleaning the appliance every morning after getting up from sleep.

III. Post prosthetic phase:

- Patients were left for a period of three months acclimatization period, at each MAL.

- During this period, the patients were instructed to wear their appliances every night upon delivery.

\section{Evaluation Method:}

CBCT (Fig. 5)

After the end of each acclimatization period, CBCT scan (SOREDEX, SCANORA 3Dx. Finland.) was performed on each awake patient while the appliance in the oral cavity.

Patient were seated upright to detect change in the UA space. Patient's head was initially oriented with the palatal plane parallel to the horizontal plane in the sagittal dimension and centered on the coronal and axial axes. This procedure established a reference plane so that all scans could be standardized to this position prior to measuring the airway (22).

Raw data obtained from CBCT-scanning were exported as DICOM format and imported into OnDemand software program (OnDemand3D ${ }^{\mathrm{TM}}$, version 1, Cybermed. Korea.) that was used to measure morphological 3D airway measurements using the volume measurement section of the software.

- The threshold level was determined for each CBCT data set individually on the basis of a different profile lines corresponding to airway area in our scope of measurement. With the profile line, it is possible to visualize a profile of the gray values or Hounsfield Units (HU), along a predefined line (23).

- UA volume was defined as the volume of the airway between two planes; the upper plane ( $\mathrm{P}$ plane) was between posterior nasal spine PNS and the basion of the skull. The lower plane passes through the most anteriorinferior point of the third cervical vertebra (C3) and parallel to the first mentioned plane.

- UA was anteriorly delimited by the soft palate, the base of the tongue, and the anterior wall of the pharynx, and posteriorly delimited by the posterior pharyngeal wall.

These parameters were used for 3D cephalometric airway analyses. A set of landmarks and planes was defined. Landmarks were identified on the sagittal view of the midsagittal plane and were checked on all other views for greater accuracy.

These anatomical parts were the closest one to the UA and were clearly observed in the sagittal plane of the CBCT images. According to the method described by Lenza et al (23).

- Based on the minimal and maximal threshold values, the corresponding 3D surfaces of the airway were segmented for airway analysis and volume was calculated.

\section{Statistical analysis:}

- To improve accuracy, all measurements were repeated 3 times, 3 days apart, and the means were used for the comparisons.

- Data were collected and entered to the computer using SPSS software package (version 21) (24).

- Kolmogorov-Smirnov test of normality revealed significance in the distribution of most of the variables, so the non-parametric statistics was adopted (25).

- The concordance correlation coefficient was used to measure the agreement between two variables, e.g., to evaluate reproducibility or for inter-rater reliability (26).

- Data were described using minimum, maximum, mean, standard deviation and 95\% CI of the mean, median and inter-quartile range.

- Mann-Whitney U test was carried out between two studied groups (27).

- Friedman's test was used among related-samples (28).

- Box and Whiskers plot was used accordingly.

An alpha level was set to $5 \%$ with a significance level of $95 \%$, and a beta error accepted up to $20 \%$ with a power of study of $80 \%$. 


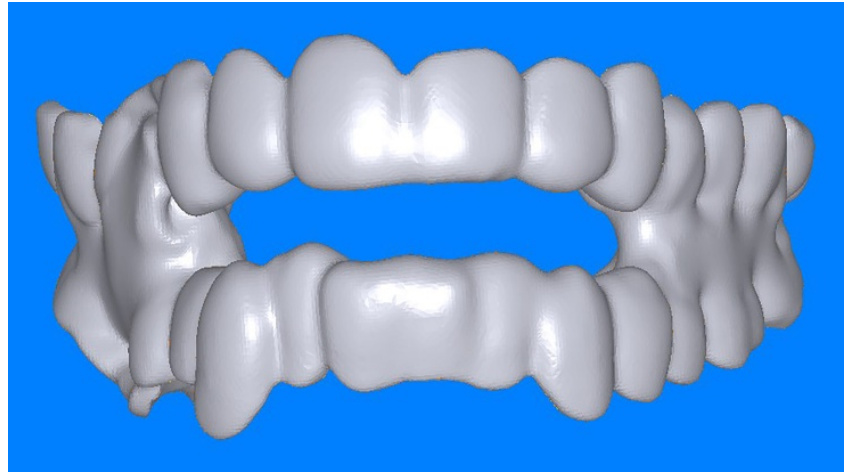

Figure 1: Monoblock MAA Design

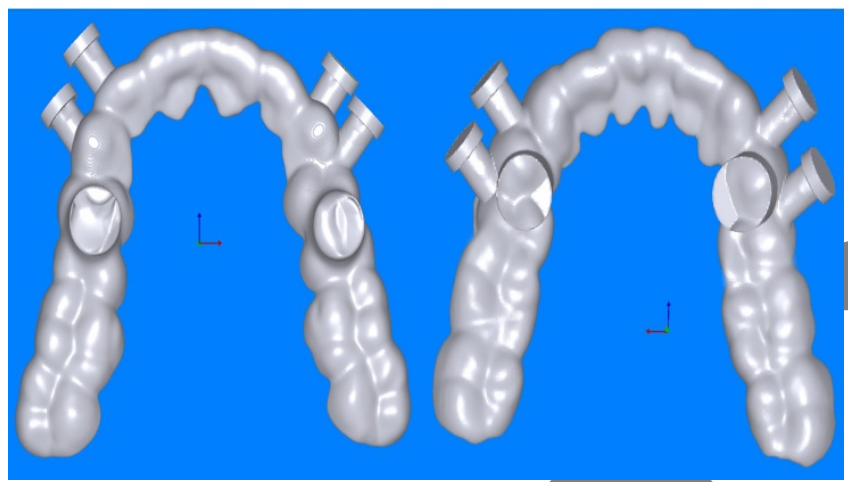

Figure 2: Biblock MAA Design

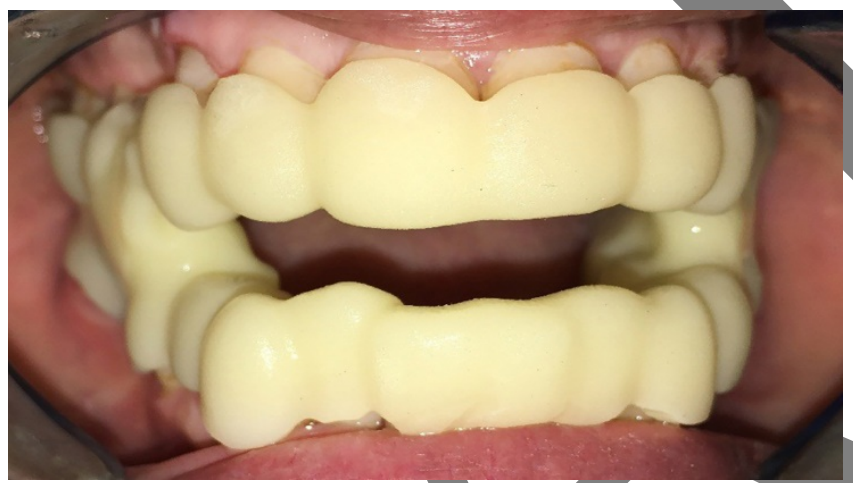

Figure 3: Intraoral view of Monoblock MAA

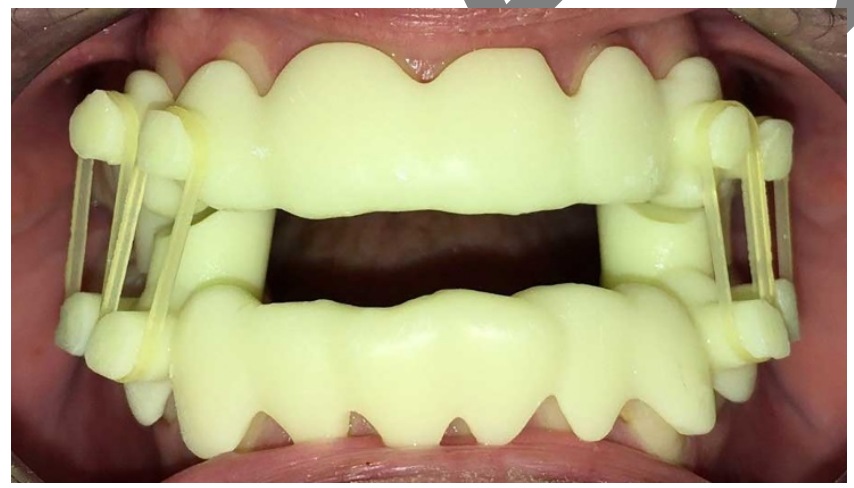

Figure 4: Intraoral view of Biblock MAA

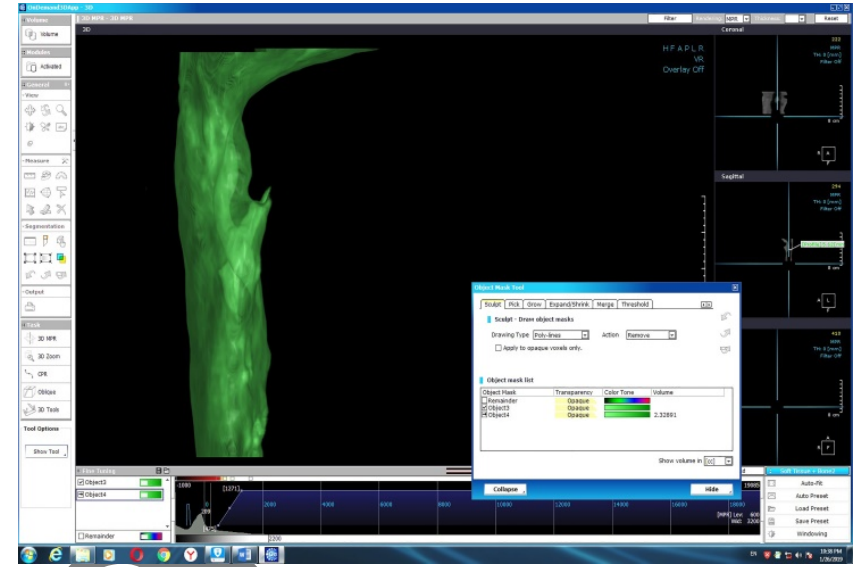

Figure 5: Upper Airway Volume measurements (CBCT)

\section{RESULTS}

The concordance correlation coefficient (for intra-rater agreement) for the three airway volume measurements was (0.996) for the baseline measurement, (0.995) for 50\% advancement measurement, and (0.993) for $75 \%$ advancement measurement. There was excellent agreement between measurements, since its value was close to 1 .

Table (1) and figure (6) shows UA volumetric changes in cubic centimeter (cc) compared to baseline measurements for both groups of MAA (Monoblock \& Biblock) through two different MAL.

By comparing UA volume between Monoblock and Biblock groups, there was no statistical significant difference at baseline $(p=.096)$ with (median=8.947) and (median=7.563) respectively. The same non-significant values were present between Monoblock and Biblock groups at 50\% mandibular advancement level $(p=.762)$ with (median=11.711) and (median=12.183) respectively.

On the reverse, at $75 \%$ mandibular advancement level, Biblock group showed statistically significant increase in UA volume (median=15.750) compared to Monoblock group (median=13.053), $(p=.001)$

As regard to $50 \%$ MAL, there was significant increase in UA volume percentage change from baseline among Biblock group (median=70.074\%) compared to Monoblock group (median=36.553\%), $(p=.016)$

The same significant increase in UA volume percentage change from baseline was found among Biblock group (median=114.861\%) compared to Monoblock group (median=42.191\%), $(p=.001)$ at $75 \%$ MAL. 


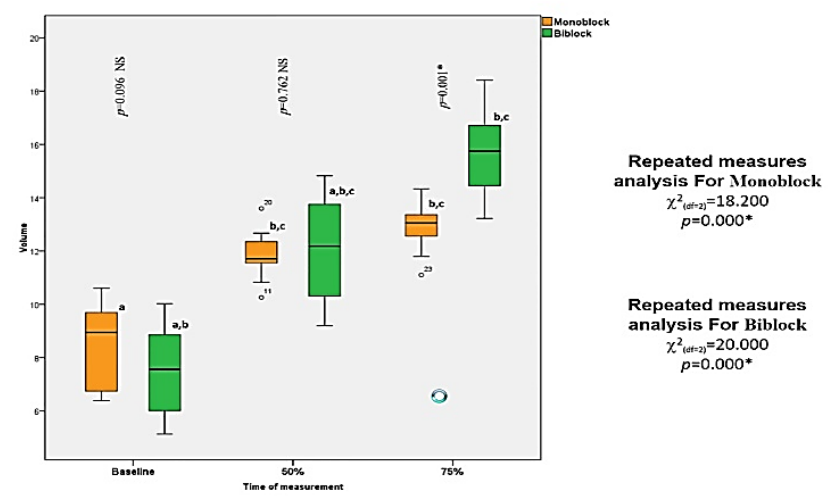

Figure 6: Box and whisker graph of Volume in the studied groups, the thick line in the middle of the box represents the median, the box represents the inter-quartile range (from $25 \%$ to $75 \%$ ), and the whiskers represent the minimum and maximum after excluding outliers (blackfilled circles) and extremes (black triangle)

Table (1): Comparison between UA volumetric measurements in cc of Monoblock and Biblock MAA groups regarding different mandibular advancements.

\begin{tabular}{|c|c|c|c|}
\hline & $\begin{array}{c}\text { Monoblock group } \\
(\mathrm{n}=10)\end{array}$ & $\begin{array}{c}\text { Biblock group } \\
(\mathrm{n}=10)\end{array}$ & $\begin{array}{c}\text { Test of } \\
\text { significance } \\
p \text { value }\end{array}$ \\
\hline \begin{tabular}{|l} 
Volume Baseline \\
$: \quad$ n \\
$: \quad$ Min-Max \\
$: \quad$ Mean $=$ Std. Deviation \\
$: \quad$ Ser Cf for mean \\
$: \quad$ Median (IQR) \\
KS test of normality
\end{tabular} & $\begin{array}{c}10 \\
6.386-10.608 \\
8.5301 .507 \\
7.451-9.607 \\
8.947^{\circ}(6.744-9.697) \\
D=0.182, p=0.200 \mathrm{NS}\end{array}$ & $\begin{array}{c}10 \\
5.129 .10 .024 \\
7.337=1.267 \\
6.144 .8 .528 \\
7.563^{2,2}(6.011 .8 .862) \\
\mathrm{D}=0.149, \mathrm{p}=0.200 \mathrm{NS}\end{array}$ & $\begin{array}{l}\mathrm{Z}_{\mathrm{anin}}=1.663 \\
p=0.096 \mathrm{NS}\end{array}$ \\
\hline $\begin{array}{l}\text { Volume at } 50 \% \text { MAL } \\
: \quad \text { aa } \\
: \quad \text { Min-Max } \\
: \quad \text { Mean }=\text { Std. Deviation } \\
: \quad \text { S5\% CI for mean } \\
: \quad \text { Median (IRR) } \\
\text { KS test of normality }\end{array}$ & $\begin{array}{c}10 \\
10.258-13.594 \\
11.45=0.928 \\
11.111 .12 .58 \\
11.7116<(11.556-12.353) \\
D=0.178, p=0.200 \mathrm{NS}\end{array}$ & $\begin{array}{c}10 \\
9.200-14.821 \\
12.144=2.036 \\
10.691-13.605 \\
12.1332 .0 .6(10.1313-13.755) \\
D=0.195, p=0.200 \mathrm{NS})\end{array}$ & $\begin{array}{l}Z_{\text {anit) }}=0.302 \\
p=0.762 \mathrm{NS}\end{array}$ \\
\hline $\begin{array}{l}\text { Volume percentage change (50\%- baseline) } \\
: \quad \text { ma } \\
: \quad \text { Min-Max } \\
: \quad \text { Mean } \pm \text { Std. Deviation } \\
\text { 99\% CI for mean } \\
: \quad \text { Median (IRR) } \\
\text { KS test of normality } \\
\end{array}$ & $\begin{array}{c}10 \\
19.084 .93 .454 \\
42.088 \pm 23.004 \\
25.631 .58 .543 \\
36.553 \%(24.532 .52 .108) \\
D=0.228, p=0.151 \mathrm{NS}\end{array}$ & $\begin{array}{c}10 \\
42.745 .87 .904 \\
68.075=15.870 \\
56.722 .79 .427 \\
70.074 \%(55.058 .79 .918) \\
\mathrm{D}=0.166, \mathrm{p}=0.200 \mathrm{NS}\end{array}$ & $\begin{array}{c}\mathrm{Z}_{(\mathrm{ani})}=2.419 \\
p=0.016^{*}\end{array}$ \\
\hline $\begin{array}{l}\text { Volume at 75\% MAL } \\
: \quad \text { aa } \\
: \quad \text { Min-Max } \\
: \quad \text { Mean } \neq \text { Std. Deviation } \\
: \quad 95 \% \text { CI for mean } \\
: \quad \text { Median (IIR) } \\
\text { KS test of normality }\end{array}$ & $\begin{array}{c}10 \\
11.100 .14 .330 \\
12.933 \pm 0.938 \\
12.2622 .13 .604 \\
13.053 \cos (12.558 .13 .361) \\
\mathrm{D}=0.225, \mathrm{p}=0.163 \mathrm{NS}\end{array}$ & $\begin{array}{c}10 \\
13.223 .18 .414 \\
13.58441 .617 \\
14.427 .16 .670 \\
15.7506(14.450 .16 .711) \\
\mathrm{D}=0.117 . \mathrm{p}=0.200 \mathrm{NS}\end{array}$ & $\begin{array}{c}\mathrm{Z}_{\mathrm{aany}=3.326}{ }_{p=0.001^{*}} \\
\end{array}$ \\
\hline $\begin{array}{l}\text { Volume percentage change } 75 \text { baseline } \\
: \quad \text { Ma pen-Max } \\
: \text { Mean } \pm \text { Std. Deviation } \\
: \text { MS\% CI for mean } \\
\text { Median (IQR) } \\
\text { KS test of normality }\end{array}$ & $\begin{array}{c}10 \\
31.237 .116 .992 \\
55.756 \pm 29.435 \\
34.969 .76 .812 \\
42.191 \%(34.599 .75 .267) \\
\mathrm{D}=0.272, \mathrm{p}=0.034^{*}\end{array}$ & $\begin{array}{c}10 \\
79.638 .160 .714 \\
118.350 \pm 30.128 \\
96.797 .139 .901 \\
114.861 \%(87.612 .152 .114) \\
\mathrm{D}=0.169 . \mathrm{p}=0.200 \mathrm{NS}\end{array}$ & $\begin{array}{c}\mathrm{Z}_{\mathrm{Aany}=3.3 .175} \\
p=0.001^{*}\end{array}$ \\
\hline $\begin{array}{ll}\text { Friedman Test } & \text { Chi-Square } \\
& \text { D }\end{array}$ & 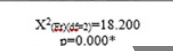 & $\begin{array}{l}\mathrm{X}^{2} \cos (\cos 2)=20.00 \\
\mathrm{D}=0.000^{*}\end{array}$ & \\
\hline
\end{tabular}

$\mathrm{n}$ : Number of patients na: number of appliances Min-Max: Minimum - Maximum

CI: Confidence interval

IQR: Inter-quartile range

KS: Kolmogorov-Smirnov

MW: Mann-Whitney U test

Fr: Friedman Test

$\mathrm{df}=$ degree of freedom

* : Statistically significant $(\mathrm{p}<0.05)$

NS: Statistically not significant $(\mathrm{p} \geq 0.05)$

Letters assigned to amount of advancement are (a) for baseline, (b) for $50 \%$, (c) for $75 \%$

Superscript letters indicate pair-wise statistical significant difference using Dunn-Sidek method

\section{DISCUSSION}

The objective of the present study was to evaluate volumetric measurements of the upper airspace of patients with OSA following wearing two different designs of MAA. MAAs used in this study were fabricated by CAD/CAM technology as it was strongly recommended by various studies due to its accuracy and adaptability (2931).

The other reason for selecting CAD/CAM technology for fabrication of Monoblock MAA was its production as one-piece in one step, on the reverse to the traditional method that fabricated the appliance as twopiece then fused them together by adhesive material which may reduce its accuracy (14).

The Biblock MAA was modified by using orthodontic elastics that were chosen as it was thought to allow lateral movement of the mandible that was more comfortable to the patient in relation to the rigid mandibular fixed position.

It was observed that all patients participating in this study were satisfied by their printed out appliance material (NextDent, Netherlands) with no complaints and this can be related to its biocompatibility and surface properties (32).

Recent advances in CBCT technology with software packages had allowed airway volumetric data to be collected from CBCT scans. These technological advances allowed progress to be made in resolving and predicting the efficacy of MAA for treatment of patients with OSA, so it was used in this study as advised by previous studies $(33,34)$.

The chosen points and planes for UA volume measurements in this study were selected due to their proximity to the UA, as well as their clear CBCT image in the sagittal plane. These were the most readily available and reliable parts for determining the limit of airway (23). Three dimensional (3D) volumetric analysis of UA gives a full picture of the anatomical characteristics of the UA which can help localizing the eventual obstacle to a normal breathing pattern and improve the diagnosis. This supports the choice of volumetric airway measurement in the present study (23).

On the same line, it was documented that UA cannot be accurately expressed by single linear measurements as performed on cephalograms $(14,23)$. This study demonstrated an increase in volumetric measurement related to both designs of MAA either at $50 \%$ or $75 \%$ MAL. This can be explained through the fact that the mandibular advancement theoretically stretches the soft palate with a concomitant stiffening of the wall of the oropharynx itself. This is accomplished through the bracing effect of the lateral wall of the soft palate in relation to the base of the tongue via the palatoglossal arch (35).

The same explanation was related to that a transverse widening of the airway with advancement is said to occur because of less movement of the hyoid bone forward than that of the mandible. This is explained because the posterior belly of the digastric muscle and the 
infrahyoid muscles mostly restrict this inferior bone. Another hypothesis is that the transverse widening effect is due to a reflex response of the stylopharyngeus muscle to the drag effect upon hyoid bone when using a mandibular advancing appliance (35-37).

So the more mandibular advancement, the more widening of the UA, that justifies the better results of both designs at $75 \%$ than that at $50 \%$, this was also approved by Arab et al (16).

In this study, Biblock MAA showed better volumetric percentage change in comparison to Monoblock MAA, this can be attributed to that; the twopiece MAA allowed greater range of mandibular movements than one-piece MAA did. Therefore, they tend to be more comfortable. Furthermore, Johal et al (38) reported that a two-piece appliance is preferred by the patient over one-piece appliance which supports the same finding of the current study.

There is another explanation for the better results of Biblock MAA, as it maintained mandibular advancement while permitting some lateral jaw movement, jaw opening, or jaw closing that may reduce the risk of complications and achieve better patient acceptance in comparison to the rigid fixation of both maxilla and mandible in Monoblock MAA.

Regarding the reported enlargement of the UA volume in this study, it can be related to the documented results of Nacher et al (39) study who stated that OSA cause systemic inflammatory response. Considering that specifically in the UA segment, adherence to oral appliance use cause resolution of the inflammation caused by OSA, then the inflamed pharyngeal wall get thinned, that widened the airway volume in that segment (40). Thus the more effective is the MAA, the more resolution of OSA symptoms, the more increase in UA volume.

The greatest point of benefit from the MAA is the total increase in volumetric change when treating OSA. Thus, it is assumed that this gain in volume allowed more airflow, and thus improvement in OSA symptoms.

\section{CONCLUSIONS}

- Mandibular repositioning treatment with MAA either Monoblock or Biblock produced statistically significant increase in UA volume of OSA patients and should be among the first considered choices for treatment on a wide variety of patients.

- Biblock MAA with elastics presented statistically significant favorable increase in UA volume in relation to Monoblock MAA.

- $75 \%$ mandibular advancement MAA in both designs produced increased volumetric change in UA segment in comparison to 50\% mandibular advancement MAA.

- CAD/CAM technique produced accurate, comfortable and fitted MAA that can be used successfully for treatment of mild-moderate OSA patients.

\section{Acknowledgment}

I would like to thank my dear professors and colleagues for their continuous support during conduction of this study.

Alexandria Dental Journal. Volume 45 Issue 2

\section{Conflict of interest}

The authors declared that they had no conflicts of interest.

\section{REFERENCES}

1. American Academy of Sleep Medicine (AASM) AASM. ICSD-3 Online Version [Last accessed on 2019 Jan 27]. Available from: http://www.aasmnet.org/store/product.aspx?pid=849.

2. Rodríguez-Lozano FJ, Sáez-Yuguero RM, Linares ET, Bermejo AF. Sleep apnea and mandibular advancement device. Reyision of the literature. Med Oral Patol Oral Cir Bucal. 2008;13: E549-54.

3. Giles TL, Lasserson TJ, Smith BH, White J, Wright J, Cates CJ. Continuous positive airways pressure for obstructive sleep apnoea in adults. Cochrane Database Syst Rev. 2006 ;3:CD001106.

4. McArdle N, Devereux G, Heidarnejad H, Engleman HM, Mackay TW, Douglas NJ. Long-term use of CPAP therapy for sleep apnea/hypopnea syndrome. Am J Respir Crit Care Med. 1999;159:1108-14.

5. Yetkin O, Kunter E, Gunen H. CPAP compliance in patients with obstructive sleep apnea syndrome. Sleep Breath. 2008;12:365-7.

6. Kushida CA, Morgenthaler TI, Littner MR, Alessi CA, Bailey D, Coleman Jr J, et al. Practice parameters for the treatment of snoring and obstructive sleep apnea with oral appliances: an update for 2005. Sleep. 2006; 29:240-3.

7. Ramar K, Dort LC, Katz SG, Lettieri CJ, Harrod CG, Thomas SM, Chervin RD. Clinical practice guideline for the treatment of obstructive sleep apnea and snoring with oral appliance therapy: an update for 2015. J Clin Sleep Med. 2015;11:773-827.

8. Cobo JM, de Carlos F, Suarez AA. "Mandibular advancement device (MAD $\left.{ }^{\circledR}\right)$ to treat sleep apnoea Hypopnoea syndrome and chonic snoring": 25th Southern Biomedical Engineering Conference 2009, Miami, Florida, USA. IFMBE Proc. 2009;24:349-54.

9. Scherr SC, Dort LC, Almeida FR, Bennett KM, Blumenstock NT, Demko BG, et al. Definition of an effective oral appliance for the treatment of obstructive sleep apnea and snoring: a report of the American Academy of Dental Sleep Medicine. J Dent Sleep Med. 2014;1:39-50.

10. Ahrens A, McGrath C, Hägg U. A systematic review of the efficacy of oral appliance design in the management of obstructive sleep apnoea. Eur J Orthod. 2011;33:31824.

11. Jayesh SR, Bhat WM. Mandibular advancement device for obstructive sleep apnea: An overview. J Pharm Bioallied Sci. 2015; 7: S223-5.

12. Sutherland K, Vanderveken OM, Tsuda H, Marklund M, Gagnadoux F, Kushida CA, et al. Oral appliance treatment for obstructive sleep apnea: an update. J Clin Sleep Med. 2014 ;10:215-27.

13. Robertson C, Herbison P, Harkness M. Dental and occlusal changes during mandibular advancement splint therapy in sleep disordered patients. Eur J Orthod. 2003; 25:371-6. 
14. AbdElmoniem AA. Fixed position versus adjustable mandibular advancement prostheses for treatment of obstructive sleep apnea. Master thesis, Faculty of Dentistry, Alexandria University, 2006.

15. Sharma SK, Katoch VM, Mohan A, Kadhiravan T, Elavarasi A, Ragesh $\mathrm{R}$ et al. Consensus and evidencebased Indian initiative on obstructive sleep apnea guidelines 2014. Lung India. 2015;32:422-34.

16. Aarab G, Lobbezoo F, Hamburger HL, Naeije M. Effects of an oral appliance with different mandibular protrusion positions at a constant vertical dimension on obstructive sleep apnea. Clin Oral Investig. 2010;14:339-45.

17. Kim J, Shin W. How to do random allocation (randomization). Clin Orthop Surg. 2014;6:103-9.

18. Chung F, Yang Y, Brown R, Liao P. Alternative scoring models of STOP-Bang questionnaire improve specificity to detect undiagnosed obstructive sleep apnea. J Clin Sleep Med. 2014;10:951-8.

19. Chang Y, Koenig LJ, Pruszynski JE, Bradley TG, Bosio JA, Liu D. Dimensional changes of upper airway after rapid maxillary expansion: a prospective conebeam computed tomography study. Am J Orthod Dentofac. 2013;143:462-70.

20. Iwasaki T, Saitoh I, Takemoto Y, Inada E, Kakuno E, Kanomi R, et al. Tongue posture improvement and pharyngeal airway enlargement as secondary effects of rapid maxillary expansion: a cone-beam computed tomography study. Am J Orthod Dentofac. 2013;143:235-45.

21. Abdallah RM, Rashad HA, Kashef NA, El-Sheikh MN. The effect of changes in the intermaxillary distance in mandibular advancement splints as a treatment of obstructive sleep apnea. Tanta Dent J. 2016; 13: 193-8.

22. Chiang CC, Jeffres MN, Miller A, Hatcher DC. Threedimensional airway evaluation in 387 subjects from one university orthodontic clinic using cone beam computed tomography. Angle Orthod. 2012;82:985-92.

23. Lenza MG, De Lenza MM, Dalstra M, Melsen B, Cattaneo PM. An analysis of different approaches to the assessment of upper airway morphology: a CBCT study. Orthod Craniofac Res. 2010,13:96-105.

24. IBM Corp. IBM SPSS Statistics for Windows, Version 21.0. Armonk, NY: IBM Corp.; Released 2012.

25. Field A. Discovering Statistics Using IBM SPSS Statistics. 4th ed. London, California, New Delhi: SAGE Publications Ltd, 2013.

26. Nickerson CA. A note on" A concordance correlation coefficient to evaluate reproducibility". Biometrics. 1997: $1503-7$.

27. Mann HB, Whitney DR. On a test of whether one of two random variables is stochastically larger than the other. The annals of mathematical statistics. 1947;1: 50-60.
28. Friedman M. The use of ranks to avoid the assumption of normality implicit in the analysis of variance. Journal of the american statistical association. 1937; 32: 675-701.

29. Al-Dwairi Z, Tahboub KY, Baba NZ, Goodacre CJ, Özcan M. A Comparison of the Surface Properties of CAD/CAM and Conventional Polymethylmethacrylate (PMMA). J Prosthodont. 2019;2:1-6.

30. Tasaka A, Matsunaga S, Odaka K, Ishizaki K, Ueda T, Abe S, et al. Accuracy and retention of denture base fabricated by heat curing and additive manufacturing. J Prosthodont Res. 2019;63:85-9.

31. Soltanzadeh P, Suprono MS, Kattadiyil MT, Goodacre C, Gregorius W. An In Vitro Investigation of Accuracy and Fit of Conventional and CAD/CAM Removable Partial Denture Frameworks. J Prosthodont. 2018; 8;19.

32. https://nextdent.com/\#materials-op.

33. Kavand G, Lagravère M, Kula K, Stewart K, Ghoneima A. Retrospective CBCT analysis of airway volume changes after bone-borne vs tooth-borne rapid maxillary expansion. Angle Orthod. 2019;15:1-9.

34. Dos Santos Trento G, Moura LB, Spin-Neto R, Jürgens PC, Gabrielli MA, Pereira-Filho VA. Comparison of Imaging Softwares for Upper Airway Evaluation: Preliminary Study. Craniomaxillofac Trauma Reconstr. 2018;11:273-7.

35. Tsuiki S, Lowe AA, Almeida FR, et al. Effects of mandibular advancement on airway curvature and obstructive sleep apnoea severity. Eur Respir J. 2004; 23:263-8.

36. Shi H, Scarfe WC, Farman AG. Upper airway segmentation and dimensions estimation from conebeam CT image datasets. Int J Cars. 2006; 1:177-86.

37. Ogawa T, Enciso R, Memon A, et al. Evaluation of 3D airway imaging of obstructive sleep apnea with conebeam computed tomography. Stud Health Technol Inform. 2005: 111:365-8.

38. Johal A, Battagel JM. Current principles in the management of obstructive sleep apnoea with mandibular advancement appliances. $\mathrm{Br}$ Dent J. 2001;190:532-6.

39. Nacher M, Serrano-Mollar A, Farre R, Panes J, Segui J, Montserrat JM. Recurrent obstructive apneas trigger early systemic inflammation in a rat model of sleep apnea. Respir Physiol Neurobiol. 2007; 155: 93-6.

40. Haskell JA, McCrillis J, Haskell BS, Scheetz JP, Scarfe WC, Farman AG. Effects of mandibular advancement device (MAD) on airway dimensions assessed with cone-beam computed tomography. Semin Orthod. 2009; 15: 132-8. 